Teresa C. Kearney*, Mark Keith and Ernest C.J. Seamark

\title{
New records of bat species using Gatkop Cave in the maternal season
}

DOI 10.1515/mammalia-2015-0043

Received March 12, 2015; accepted December 15, 2015

\begin{abstract}
Eight bat species were recorded at Gatkop Cave, in the northern part of South Africa in December 2011 (Cloeotis percivali, Hipposideros caffer, Myotis tricolor, Miniopterus natalensis, Nycteris thebaica, Rhinolophus blasii, Rhinolophus smithersi, and Rhinolophus simulator). With the exception of M. natalensis, R. simulator and Myo. tricolor, the other five species were recorded for the first time at Gatkop Cave during this time of the year, when thousands of $M$. natalensis use the cave as a maternity and nursery roost. Previously it was suggested the large numbers of $M$. natalensis using Gatkop Cave during the maternal period excluded other bat species. The reason for this recorded change in species roost composition at Gatkop Cave during the maternal period in relation to previous records made from the late 1960s and the mid 1980s is not clear, two possible reasons are the loss of other roosts, or these species were previously present but were not captured as a result of the particular methods used.
\end{abstract}

Keywords: Chiroptera; conservation; Gatkop Cave; maternity cave; new records; South Africa.

\section{Introduction}

Bats as volant, nocturnal animals occupy a unique ecological niche. Most of the cave dwelling bat species in South Africa are insectivorous (Monadjem et al. 2010), and feeding on nocturnal insects they provide valuable ecological services to the environment, and economic services to man (Boyles et al. 2011, Kunz et al. 2011). Although not

*Corresponding author: Teresa C. Kearney, AfricanBats, 357 Botha Avenue, Kloofsig, 0157, South Africa; School of Animal, Plant and Environmental Sciences, University of Witwatersrand, Private Bag 3, Wits 2050, South Africa; and Ditsong National Museum of Natural History, PO Box 413, Pretoria, 0001, South Africa, e-mail: Teresa.Kearney@africanbats.org

Mark Keith and Ernest C.J. Seamark: AfricanBats, 357 Botha Avenue, Kloofsig, 0157, South Africa; and Centre for Wildlife Management, University of Pretoria, Private Bag X20 Hatfield, Pretoria 0028, South Africa yet quantified for cave dwelling species in South Africa, these services may extend over fairly large areas as many cave-dwelling species in Australia and Malaysia have been shown to travel considerable distances at night to forage (Thomson 2002, Struebig et al. 2009, Vincent et al. 2011). The increased scale of these valuable ecological and economic services provided by large colonies of cave roosting bats has been documented in the USA (Cleveland et al. 2006). The diurnal roosts of bats are important as they offer protection from exposure to day-time ambient conditions and predators, promote energy conservation, and facilitate social interactions (Kunz and Lumsden 2003). Caves can often contain a number of different bat species that roost differently, selecting different parts of a cave, with the appropriate micro-climatic conditions to best suit the species-specific metabolic or physiological requirements for survival and reproduction (Racey and Entwistle 2003). The micro-climatic roost requirements of some bat species may also vary in different seasons, to the extent that they need to change roosts in winter and summer (Fleming and Eby 2003).

Cave roost sites are a limited resource as they are usually rare and unevenly distributed features of most landscapes (Struebig et al. 2009). Bat species throughout the world are vulnerable to the destruction of their roosts, as well as to roost disturbance, and these issues are of real concern for long-term conservation of bat populations (Hutson et al. 2001, Mickleburgh et al. 2002). When large numbers of bats are concentrated in a few roost sites, they are extremely vulnerable to risks of disturbance or roost destruction. Despite their small size, bats have low reproductive rates and long generation times, and cannot sustain elevated rates of mortality or depressed levels of recruitment (Sheffield et al. 1992). For this reason, the preservation and conservation of bat roosts, in particular cave roosts, is probably the most important issue in bat conservation (Sheffield et al. 1992). Loss or disturbance to cave roost sites may not only have detrimental consequences for the bat populations they support, but may also have knock on effects elsewhere in a landscape if no other alternative roost sites are available (Struebig et al. 2009). In view of this; in order to conserve cave roosting bat species diversity and not lose their environmental and economic services, it is important to know where roosts of 
cave roosting bats are (especially maternity roosts), which species are using them, for what purpose, and the size of the populations. This information is necessary for individual species IUCN Red List assessments, and will also allow prioritization of the value of different cave roosts, and being available for conservation area planning, will allow scarce resources to be focused on more valuable roost sites.

One such cave of particular importance in South Africa, is Gatkop Cave $\left(24^{\circ} 37^{\prime} \mathrm{S} 27^{\circ} 39 \mathrm{E}\right)$, east of Thabazimbi in Limpopo Province, in the north of South Africa. Since the turn of the 20th century, Gatkop Cave has featured in numerous museum collections as a result of contributions of specimens of cave roosting bats from this cave (see below for more detail). Variations in locality descriptions, and in farm names and numbers initially confused the identification of Gatkop Cave, however, the cave locality was confirmed (M. van der Merwe, pers. comm., 24/01/2012) to be the same as that previously referred to as Sandspruit Cave, or Zandspruit or Sandspruit Cave No. 1 and No. 2, on museum specimens (Ditsong National Museum of Natural History (DNMNH), Pretoria (previously Transvaal Museum - TM) - DNMNH 12617-12618, 13960-13963, 13995-13999, 15574, 25414; Field Museum of Natural History, Chicago - FMNH 152608, 152535; Royal Ontario Museum, Toronto - ROM 45719-45740, 45813, 48684, 48686, 77813-77819, 83938; Senckenberg Museum, Frankfurt - SMF 19560-19561) and in publications (van der Merwe 1973, 1975, 1979, 1980, 1989, Norton and van der Merwe 1978, Rautenbach 1982, van der Merwe and van Aarde 1989). The latter names were in reference to the farm Zandspruit/Sandspruit, on which the cave was situated prior to the current property subdivisions. The name Gatkop appears to be in reference to the name indicated on the 1968 1:50 000 Surveyor General map sheet, associated with a point 4284 feet above sea level, approximately $3.75 \mathrm{~km} \mathrm{NW}$ of the entrance to the cave. This point is on the opposite side of the ridge behind the cave entrance, and on the western side of the ridge, whose highest peak on the eastern side was identified on the 1968 1:50 000 Surveyor General map sheet as Kwa-Meletse. Later, in the Readers Digest Atlas of Southern Africa (1984), the name Gatkop appears on the same side of the ridge as the cave entrance.

It is not always possible to accurately place the localities specified for older specimens, due to changes over time to place names, and, or, the manner in which, and the accuracy with which geographic localities were recorded. Two examples of this exist in relation to specimens that may have been collected from Gatkop Cave. In $1909 \mathrm{H}$. Lyster Jameson described a new species of
Miniopterus, Miniopterus breyeri Jameson 1909 [currently synonymized with Miniopterus natalensis (A. Smith, 1833) see ACR 2015], based on a female he collected at Gatkoppies Cave that was deposited in the Natural History Museum London (BMNH 1909.7.2.6) collection (Jameson, 1909). He also deposited another seven individuals from Gatkoppies, currently identified as M. natalensis, in the DNMNH collection. These included a female collected on 12 December 1902 (DNMNH 41022), and six males collected on 14 December 1906 (DNMNH 1120-1123, 1125, 1126). In the original description for M. breyeri (Jameson 1909) the locality is referred to as "the great cave at Gatkoppies, in the Waterberg District of the Transvaal", which bears considerable similarity to the locality currently referred to as Gatkop Cave.

The other example comes from bats collected during the Smithsonian Institution African Mammal Project from 1961-1972. This excerpt is from the annotated gazetteer of collection localities by Schmidt et al. (2008: 258) "The crew camped on the Buffelshoek Farm owned by H. C. Fouché, off of the road to Warmbad-Alma. Specimens tags, field catalogs, and Pretorius' journal all place the farm as " $16 \mathrm{mi}$ SE Thabazimbi", but the coordinates of Buffelshoek fall east-southeast of Thabazimbi $\left(24^{\circ} 36^{\prime} \mathrm{S}, 27^{\circ} 24^{\prime} \mathrm{E}\right)$. The farm's coordinates do intersect a point about 16 road miles from Thabazimbi (TPC, Sheet Q-5A, 1:500,000) and are consistent with other local landmarks mentioned by the collectors. A series of Miniopterus, labelled as from Buffelshoek, were taken on 15 Apr from a cave located at Gatkoppie, also along the Warmbad-Alma road but at $20 \mathrm{mi}$ [32.2 km] "SE" Thabazimbi; a Gatkop Mountain $\left(24^{\circ} 36^{\prime} \mathrm{S}, 27^{\circ} 38^{\prime} \mathrm{E}\right)$ lies due east of Thabazimbi. On 22 Apr, they obtained bats from a cave on the nearby Waterval Farm $\left(24^{\circ} 36^{\prime} \mathrm{S}, 27^{\circ} 36^{\prime} \mathrm{E}\right)$, also recorded as $16 \mathrm{mi}$ "SE" Thabazimbi but, in fact, due east of that town". Recent enquiries about caves on the farms Buffelshoek and Waterval have to date (since 2011) not identified any caves on these properties. Both the farms Buffelshoek and Waterval are adjacent to the farm on which Gatkop Cave is situated, and the cave is located at the edge of the portion, on the boundary with Waterval Farm. As with the specimens collected by Jameson (ACR 2015), it is possible the specimens collected during the Smithsonian Institution African Mammal Project: a series of male Miniopterus natalensis collected on 15 April 1969 (USNM 575304-34), and a female (USNM 575194) and two male (USMN 575198, 575201) Rhinolophus denti Thomas 1904 collected on 22 April 1969 were collected from the cave currently known as Gatkop Cave. However, there is no certainty about this, and $R$. denti has not been recorded in the area by 
any others specimens (ACR 2015), although it is possible these specimens were misidentified.

Historical records based on museum specimens from Gatkop Cave that are recorded in the African Chiroptera Report (ACR 2015), indicate this roost was used by Miniopterus natalensis in February 1966 (male collected - DNMNH 15574), May 1973 (male collected - DNMNH 20594), October 1973 (males collected-DNMNH 2059520608), and December 1973 (female collected - DNMNH 20625). Decades of research on M. natalensis, identified the importance of Gatkop Cave as a maternity roost in this region. Several site visits over the years by van der Merwe and colleagues from the late 1960s to the mid-1970s indicated the nature of this cave functioning as a maternity roost in the summer period. Data collected from November 1967 to March 1968, and October 1974 to February 1975, indicated M. natalensis females had given birth, to their single young, from the end of October, with the peak in births occurring from the end of November to the beginning of December, and females and young had subsequently left the cave by 3 March in 1968 (van der Merwe 1973, Norton and van der Merwe 1978). Recovery of banded individuals showed $M$. natalensis individuals migrated from Gatkop Cave to other caves $142 \mathrm{~km}$ south in the Cradle of Humankind World Heritage Site that are southwest of Pretoria, Gauteng, where the species are reported to hibernate for the winter (Coetzee 1965, van der Merwe 1973, 1975). This species is one of few African bat species listed in Appendix II of the Convention on the Conservation of Migratory Species of Wild Animals (CMS), effective 8 February 2015. van der Merwe (1973) estimated Gatkop Cave to be the largest maternity colony of $M$. natalensis in the northern region of South Africa. It was estimated there were 158,900 juvenile M. natalensis in Gatkop Cave in 1967 and 110,000 in 1974, relative to a smaller maternity colony at Makapans (an estimated 49,000 juvenile M. natalensis in 1967, and 59,000 in 1974) (van der Merwe 1973).

Throughout the work by van der Merwe at Gatkop Cave during the Miniopterus natalensis maternal season, i.e. from the end of October to the beginning of March, $M$. natalensis was usually the only bat species recorded at the cave (van der Merwe 1987). According to van der Merwe (1987) the exception to this was during a visit on 17 December 1984 when a small colony of 200-300 juvenile Myotis tricolor (Temminck 1832) were observed in the cave. No Myo. tricolor were observed during a subsequent visit on 26 January 1985, when the cave was still occupied by $M$. natalensis females and juveniles, and it was suggested the large number of $M$. natalensis in the maternity colony at Gatkop Cave kept other bat species away from this roost during the maternity period (van der Merwe 1987). There was no mention of a specimen in van der Merwe (1987), yet Monadjem et al. (2010) and the ACR (2015) record a specimen of Myo. tricolor (DNMNH 25414) from Gatkop Cave, which according to museum records was collected by Mac van der Merwe on 21 November 1974. Maternity colonies with fewer individuals of Cloeotis percivali Thomas 1901, Myo. tricolor, Nycteris thebaica E. Geoffroy St.-Hilaire, 1818 and Rhinolophus simulator K. Andersen 1904, had been observed at a smaller cave, Rookpoort Guano Cave [29 $39^{\prime} \mathrm{S} 27^{\circ} 44^{\prime} \mathrm{E}$ as recorded by van der Merwe (1973)], nine km away from Gatkop Cave, on 10 December 1967 (van der Merwe 1987). The direction of Rookpoort Guano Cave relative to Gatkop Cave was reported as south-east by van der Merwe (1973), and north-west by van der Merwe (1987). The latter is in error, reflecting instead the direction of Gatkop Cave relative to Rookpoort Guano Cave.

Outside the Miniopterus natalensis maternity period, on 8 June 1968, van der Merwe (1987) observed four Rhinolophus species (Rhinolophus blasii Peters 1867, Rhinolophus clivosus Cretzschmar 1828, Rhinolophus hildebrandtii (now referred by Taylor et al. (2012) to Rhinolophus smithersi Taylor, Stoffberg, Monadjem, Schoeman, Bayliss and Cotterill 2012), and Rhinolophus simulator) using Gatkop Cave as a roost. No specimen records are known to exist to verify the observation of $R$. clivosus occurring at Gatkop Cave (van der Merwe 1987), but there are museum specimens for the other three Rhinolophus species from Gatkop Cave reported in the African Chiroptera Report (ACR 2015) for dates outside the maternity period. Some of these records were also reported in Monadjem et al. (2010). There are specimens of $R$. blasii collected on 19 August 1962 (DNMNH 13960-13963), 3 June 1967 (DNMNH 1399513999, FMNH 152535, ROM 45719, 45729-45730, 45736-45737, 45813, 48686, 77818-77819, 83938), and 13 September 2005 (DNMNH 47766); a single R. darlingi (ROM 77817) collected on 3 June 1967, whose identity still needs to be verified; $R$. smithersi (previously recorded as R. hildebrandtii) collected on 14 and 16 June 1958 (DNMNH 12617-12618); and R. simulator collected on 3 June 1967 (ROM 45720-45728, 45731-45735, 45738-45740, 48684, 77813-77816), and 13 September 2005 (DNMNH 47764). Kock et al. (2000) and the African Chiroptera Report (ACR 2015) also record specimens of two R. simulator females (SMF 19560 and 19561) in the Senckenberg Museum in Frankfurt that were collected at Gatkop Cave, within the M. natalensis maternity period, on 12 December 1959, which were not mentioned by van der Merwe (1987).

This work reports more recent records of other bat species collected at Gatkop Cave during the wet, summer period, while Miniopterus natalensis were using the cave as a maternity and nursery roost. 


\section{Materials and methods}

Bats were trapped outside the cave for three nights from 15 to 18 December 2011 using three harp traps of different sizes and bank numbers, strung with nylon strands (two were manufactured by one of the authors ECJS, one was from Bat Conservation and Management, Carlisle, Pennsylvania, USA). The traps were set $23 \mathrm{~m}$ and $35 \mathrm{~m}$ away from the cave entrance, so as to minimize disturbance to bats roosting in the cave. On the third night of sampling the angle of the trap capture area relative to the cave entrance was changed slightly for two of the traps. The third trap was left in the same place for all three nights. Traps were checked and emptied at various intervals throughout the emergence time from around 19:10 $\mathrm{h}$ until around 21:45 $\mathrm{h}$, when the number being caught declined. The traps were checked again around 05:30 h the next day. On 18 December 2011, three people made an hour long exploratory trip into some parts of the cave, with an Anabat SD1 detector (Titley Scientific, Brendale, Australia) to record echolocation calls of species that may not have been caught in the harp trap. In order not to unduly disturb the bats, in particular the Miniopterus natalensis maternity roost, the area where the $M$. natalensis appeared to be roosting was not entered. No attempt was made to catch bats in the cave and observations were not made during this visit of the bats themselves.

Catching and collecting was allowed by a Wildlife Trade and Regulation Permit (receipt number 1019992) from the Limpopo Province Department of Economic Development, Environmental and Tourism. The permitted number of Miniopterus natalensis were collected as voucher specimens, and the rest of those caught were released. Most bats were released immediately after having made a record of their sex, while 120 were measured, sexed and aged shortly after they were caught for a separate study on body condition index, and then released. Various external measurements and morphological characteristics were used to assign field identifications to individuals of the other species that were caught, following classifications in a number of different sources: Meester et al. (1986), Csorba et al. (2003), Monadjem et al. (2010), and ACR (2011). The exception to this were individuals assigned to $M$. natalensis, as the large majority of these individuals were released almost immediately after capture, having only been sexed. Their species identification was assumed based on the identification of individuals that were measured and released, and those taken as voucher specimens, which were all $M$. natalensis.

Due to the large number of individuals caught, age and reproductive condition was not assessed for each individual. Where it was done, individuals were assigned as adult or sub-adult, on the basis of whether or not the epiphyses on the finger bones were fused (Simmons and Voss 2009), and pelage color (sub-adults being grayer). Adult males were recorded as to whether or not testes were apparent (Racey 2009). For adult females, observations were made of the nipple region as to whether they were rudimentary or large, surrounded by hair or not, and whether the mammary gland could be seen through the skin, and the lower abdomen was investigated for signs of pregnancy (Racey 2009, Mason et al. 2010). Individuals that were not retained as voucher specimens, were released where they had been caught. These field procedures were done in accordance with guidelines of the American Society of Mammalogists (Sikes et al. 2011).

Voucher specimens were lodged in the small mammal collection at the Ditsong National Museum of Natural History; formerly Transvaal Museum (see Table 1). Skulls were extracted from voucher specimens, and their identifications assessed following characters for skulls in the same classification consulted for morphological characters, i.e. Meester et al. (1986), Csorba et al. (2003),

Table 1: Number, sex, and where recorded, the number in different age groups (ANR, Age not recorded; Ad, adult; Sub, sub-adult) of the bat species caught at Gatkop Cave in December 2011.

\begin{tabular}{|c|c|c|c|c|c|c|c|c|c|c|}
\hline \multirow[t]{2}{*}{ Species } & \multirow[t]{2}{*}{ Tot. } & \multicolumn{4}{|r|}{ Male } & \multicolumn{4}{|c|}{ Female } & \multirow[t]{2}{*}{ DNMNH accession \# } \\
\hline & & Tot. & ANR & Ad. & Sub & Tot. & ANR & Ad. & Sub & \\
\hline Cloeotis percivali & 1 & 1 & 1 & 0 & 0 & 0 & 0 & 0 & 0 & 48462 \\
\hline Hipposideros caffer & 2 & 2 & 2 & 0 & 0 & 0 & 0 & 0 & 0 & $48454-48455$ \\
\hline Rhinolophus blasii & 5 & 3 & 1 & 0 & 2 & 2 & 0 & 1 & 1 & $48450-48453,48461$ \\
\hline Rhinolophus simulator & 31 & 16 & 16 & 0 & 0 & 15 & 4 & 11 & 0 & $48437-48443$ \\
\hline Nycteris thebaica & 6 & 1 & 1 & 0 & 0 & 5 & 0 & 4 & 1 & $48457-48460$ \\
\hline Miniopterus natalensis & 690 & 44 & 0 & 44 & 0 & 646 & 0 & 645 & 1 & 48444-48449 \\
\hline Myotis tricolor & 1 & 0 & 0 & 0 & 0 & 1 & 0 & 0 & 1 & 48456 \\
\hline
\end{tabular}

Descriptions of the different age categories are given in the methods section. DNMNH accession \# indicates the number given to voucher specimens deposited in the Ditsong National Museum of Natural History. 
Monadjem et al. (2010), ACR (2015). Taylor et al. (2012) was followed for identification of the species that was previously known as Rhinolophus hildebrandtii. Skulls and mandibles of Miniopterus natalensis and the various Rhinolophus species were also measured using measurements indicated in Goodman et al. (2007) and Csorba et al. (2003). The nomenclature used follows ACR (2015) and Foley et al. (2014).

\section{Results}

The weather at Gatkop Cave on all three nights of sampling was clear, with no rain. Seven species from six families were recorded with verifiable voucher specimens, from the harp trap captures: Cloeotis percivali, Hipposideros caffer (Sundevall 1846), Rhinolophus blasii, Rhinolophus simulator, Nycteris thebaica, Myotis tricolor, and Miniopterus natalensis. The number of individuals caught for each species, as well as a breakdown by sex, and the age categories are indicated in Table 1. An additional species, Rhinolophus hildebrandtii, was documented within the cave from recordings of the echolocation call (Figure 1). Subsequently this identification has been changed to $R$. smithersi following the split of R. hildbrandtii and the description of four new species by Taylor et al. (2012).

Even though harp traps do not catch all species with equal probability (Kunz et al. 2009), as indicated by Rhinolophus smithersi not having been caught even though they were recorded in the cave with an Anabat SD1, the number of each species captured may nevertheless give some indication of the relative size of the groups of each species utilizing Gatkop Cave. The species listed in order from highest to lowest number of individuals caught were:
Miniopterus natalensis ( $\mathrm{n}=690)$, Rhinolophus simulator $(\mathrm{n}=31)$, Nycteris thebaica $(\mathrm{n}=6)$, Rhinolophus blasii $(\mathrm{n}=5)$, Hipposideros caffer $(\mathrm{n}=2)$, and Myotis tricolor, Cloeotis percivali $(\mathrm{n}=1)$. The number of $M$. natalensis caught was at least one order of magnitude larger than for the other species. Twenty-two times more $M$. natalensis were caught than $R$. simulator, the second most abundantly captured species.

Bearing in mind, the possibility that harp trap capture of individuals of different sexes and age classes might not be equal (Francis 1989, Kunz et al. 2009), and ratios based on larger sample sizes are more reliable, the sex ratio of captured males to females (Table 1) was 1:15 for Miniopterus natalensis, 1:5 for Nycteris thebaica, 1:0.67 for Rhinolophus blasii, and 1:0.94 for Rhinolophus simulator. While most individuals of the different species captured were adults, sub-adults were caught of three species: R. blasii ( $\mathrm{n}=3$ of 5), N. thebaica ( $\mathrm{n}=1$ of 6 ), and Myo. tricolor ( $n=1$ of 1). Lactating females were recorded for M. natalensis, $N$. thebaica, R. blasii and R. simulator. Adult females in non-reproductive condition (with indistinct nipples surrounded by hair, and not apparently pregnant) were recorded for $M$. natalensis and $R$. simulator, and a postlactating individual (with large, keratinized nipples, surrounded by hairless areolate, but no observable white mammary glands) was recorded for $R$. simulator. No males, of any of the species, were observed to be scrotal.

\section{Discussion}

A total of eight species were recorded at Gatkop Cave in December 2011, seven trapped in the harp-traps and recordings of Rhinolophus smithersi made within the cave.

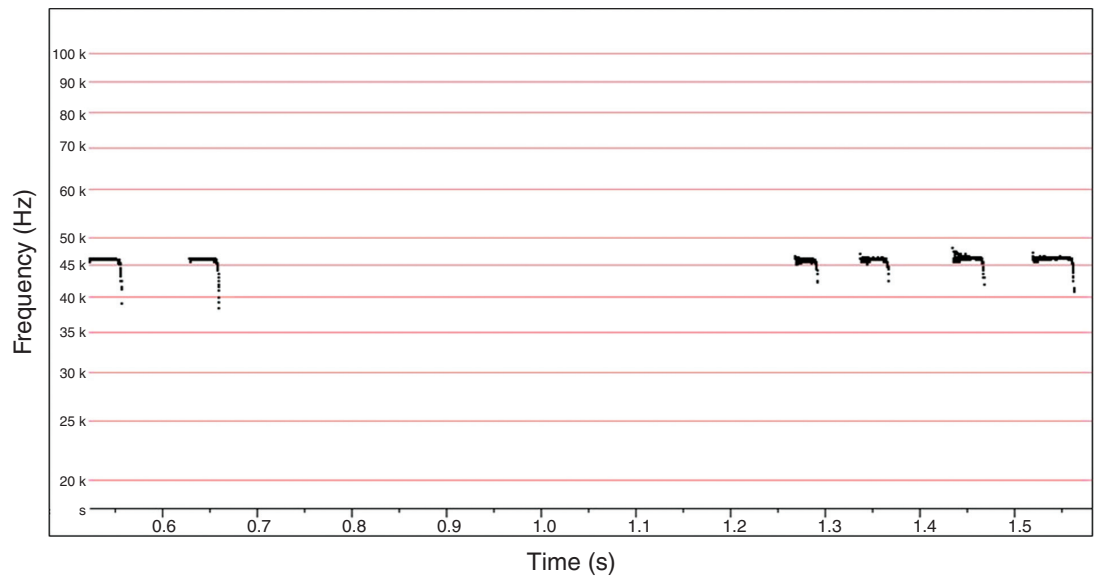

Figure 1: Time versus frequency graph of the echolocation call of Rhinolophus smithersi recorded (LC171244.44\#) free flying within Gatkop Cave on 18 December 2011. 
Previous records only documented three species (Rhinolophus simulator, Myotis tricolor, and Miniopterus natalensis) at Gatkop Cave in December, hence, five additional species were recorded for the first time in December 2011 (Cloeotis percivali, Hipposideros caffer, Rhinolophus blasii, R. smithersi, and Nycteris thebaica). Given the absence of sub-adult $M$. natalensis in the captures, it was assumed the young of $M$. natalensis were not yet flying, or venturing out of the cave. Based on captures of sub-adults, and post-lactating and lactating females of $R$. blasii, $R$. simulator, Nycteris thebaica, and Myo. tricolor, it is possible these species may also have been using Gatkop Cave as a maternity roost in 2011.

The seven species recorded at Gatkop Cave in December 2011, in addition to Miniopterus natalensis, may indicate that more bat species have begun using the cave in December since 1984, or these additional species were over-looked during the earlier research and collecting at Gatkop Cave. No recent visit has been made to Rookpoort Guano Cave, nine km SE of Gatkop Cave, to confirm if this is still being used as a maternity roost for the species that were historically documented at this cave: Cloeotis percivali, Myotis tricolor, Nycteris thebaica and Rhinolophus simulator (van der Merwe 1987), and which have now been documented in Gatkop Cave. If Rookpoort Guano Cave is no longer a viable bat roost, which may have occurred as a result of disturbance to the bats, it may explain an influx of species into Gatkop Cave. Or, if Rookpoort is still used as a roost by these species, Gatkop Cave has become an additional roost site for these species. Another explanation might be that these species, roosting in much smaller numbers than $M$. natalensis, were previously over-looked. Although previous research at Gatkop Cave involved observations of bats during visits into the cave, Gatkop Cave consists of several, large chambers, and it is possible these species may have been roosting in parts of the cave that were not accessed. Other possibilities that may account for the difference in the species recorded, are differences in the harp traps in relation to both their design and placement, as the trap that was used in the 1960s and 1970s had metal strands on springs and was placed closer to the cave entrance (M. van der Merwe, pers. comm., 24/01/2012).

According to the Regional South African IUCN Red List assessment (Friedmann and Daly, 2004) of the species recorded at Gatkop Cave in December 2011, one species was listed as Data Deficient (Hipposideros caffer), two were listed as Least Concern (Rhinolophus simulator, Nycteris thebaica), three were listed as Near Threatened (Rhinolophus smithersi [referred to as Rhinolophus hildebrandtii], Miniopterus natalensis, Myotis tricolor), and one each were listed as Vulnerable (Rhinolophus blasii) and
Critically Endangered (Cloeotis percivali). Cloeotis percivali had not previously been recorded at Gatkop Cave, although unverifiable reports of its presence at Gatkop Cave were made in September 2005 (D. Peinke, pers. comm., 12/10/2011), and September 2011 (J. Balona, pers. comm., 15/1/2012). The closest previous records of $C$. percivali to Gatkop Cave are specimens in the Royal Ontario Museum (ROM 77892 and 77893) that were collected on the 29th of December 1961, from Rooiberg, $39 \mathrm{~km}$ SE of Thabazimbi (ACR 2015). There is also a published observation of the species occurring at the nearby Rookpoort Guano Cave (van der Merwe 1987).

Given the method of capture in December 2011, in harp traps set $23 \mathrm{~m}$ and $35 \mathrm{~m}$ away from the cave entrance, it is not possible to be entirely certain if all the species recorded were roosting in the cave, and if so, whether they were using it as a day or a night roost. Brown and Berry (1997) reported "two-way traffic" in mines in the USA, where Little Brown Bats (Myotis lucifugus) and Pallid Bats (Antrocous pallidus) entered mines to utilize them as a night roost, even before Townsend's Big-eared Bats (Corynorhinus townsendii) had exited the mine they were using as a day roost. However, based on the observations of the number of bats flooding from Gatkop Cave at emergence, and the most numerous species and the sex of the individuals that were caught, it appeared Miniopterus natalensis was still using the cave as a maternity roost. Given the closest known cave roost in the area was $9 \mathrm{~km}$ away, it was assumed the other six species that were captured were also roosting in Gatkop Cave.

While the use of Gatkop Cave as a day roost throughout summer should be confirmed for the new species reported here, and further work needs to be done to ascertain the population size of each species using the cave as a roost, these results suggest the cave is an important bat roost. This is based on the high recorded species richness, species with threatened IUCN Red List statuses, and that it continues to be used as a maternity site for Miniopterus natalensis. Gatkop Cave remains one of only two known maternity roosts for $M$. natalensis in northern South Africa (van der Merwe 1973). The size of the maternity colony for M. natalensis at Gatkop Cave has not been re-evaluated since it was calculated by van der Merwe (1973). However, from observations of the bats exiting the cave in December 2011, the maternity colony of $M$. natalensis still appears to be sufficiently large to warrant concern for its protection, given the vulnerability of such a large accumulation of individuals of $M$. natalensis in a single locality during the period of recruitment. The high level of fidelity shown in the continued use of Gatkop Cave as a maternity roost by $M$. natalensis suggests preservation and conservation of 
Gatkop Cave will be important, not only for the long-term security of a large proportion of the savanna population of $M$. natalensis, but also the other species recorded at the cave in this study.

Gatkop Cave was not included by Monadjem et al. (2010) in their list of important bat cave roost. Although Monadjem et al. (2010) did make the point that all caves as landforms, unless already protected by national legislation, should hold high rank as sites of critical conservation status, they gave no indication of what criteria had been used to measure importance. Given the limited resources for conservation, it is an aim of AfricanBats (a not for profit bat conservation organization) to develop ranking criteria by which to assess the conservation needs of different bat cave roost sites in Africa, in order to better prioritize conservation action, investment and legislation. These results; documenting the continued presence of a large Miniopterus natalensis maternity roost at Gatkop Cave, as well as five other bat species not previously recorded from the cave, are a start toward this goal of understanding and prioritizing the conservation needs of African cave roosting bat species. As a template, for further refinement and testing, scores in relation to the following information could be compared between different cave roosts: the number of species using the cave roost, their population number in the roost, whether or not the roost is used for maternal or hibernation purposes and what time period they are in residence each year, the IUCN Red List status of the species using the cave roost, whether any of the species are migratory and listed by the CMS, and the distance to the next nearest known roost. These scores would provide a guide for the criteria that could be used in a ranking system to prioritize the conservation importance of different cave roosts.

Acknowledgments: The Landowner Aquila Steel (S Africa) Pty Ltd and Aquila Resources LTD, represented by Johan van Breda (Project Manager), Johann van Deventer (Explorations Manager) and Tiaan van den Berg (OHS/ Field supervisor), gave permission and provided assistance in accessing Gatkop Cave. Prof Mac van der Merwe, Dr Dean Peinke, and Mr. Julio Balona kindly shared their earlier experiences of bats at Gatkop Cave. Carlo Ornelas and Xolisa "Lucky" Soqashe assisted in the field.

\section{References}

ACR. 2011. African Chiroptera Report. 2011. African Chiroptera Project, Pretoria.

ACR. 2015. African Chiroptera Report 2015. AfricanBats, Pretoria. pp. i-xix; 7001.
Boyles, J.G., P.M. Cryan, G.F. McCracken and T.H. Kunz. 2011. Economic importance of bats in agriculture. Science 332: 41-42.

Brown, P.E. and R.D. Berry. 1997. Renewed mining and reclaimation: impacts on bats and potential mitigation. In: Proceedings of the 1997 National Meeting of the American Society of Surface Mining and Reclamation, Austin, Texas. pp. 196-201.

Cleveland, C.J., M. Betke, P. Frederico, J.D. Frank, T.G. Hallam, J. Horn, J.D. López Jr., G.F. McCracken, R.A. Medellín, A. Moreno-Valdez, C.G. Sansone, J.K. Westbrook and T.H. Kunz. 2006. Economic value of the pest control service provided by Brazilian free-tailed bats in south-central Texas. Front. Ecol. Environ. 4: 238-243.

Coetzee, C.G. 1965. Bat banding in southern Africa. News Bull. Zool. Soc. S. Afr. 7: 8-10.

Csorba, G., P. Ujhelyi and N. Thomas. 2003. Horseshoe bats of the world (Chiroptera: Rhinolophidae). Alana Books, Shropshire. pp. xxx; 160.

Fleming, T.H. and P. Eby. 2003. Ecology of bat migration. In: (T.H. Kunz and M.B. Fenton, eds.) Bat ecology. The University Chicago Press, Chicago and London. pp. 156-208.

Foley, N.M., V.D. Dinh Thong, P. Soisook, S.M. Goodman, K.N. Armstrong, D.S. Jacobs S.J. Puechmaille and E.C. Teeling. 2014. How and why overcome the impediments to resolution: Lessons from rhinolophid and hipposiderid bats. Mol. Biol. Evol. 32: 313-333.

Francis, C.M. 1989. A comparison of mist nets and two designs of harp traps for capturing bats. J. Mamm. 70: 865-870.

Friedmann, Y. and B. Daly. 2004. Red data book of the mammals of South Africa: a conservation assessment. CBSG Southern Africa, Conservation Breeding Specialist Group (SSC/IUCN), Endangered Wildlife Trust., South Africa. pp. 722.

Goodman, S.M., K.E. Ryan, C.P. Maminirina, J. Fahr, L. Christidis and B. Appleton. 2007. Specific status of populations on Madagascar referred to Miniopterus fraterculus (Chiroptera: Vespertilionidae), with description of a new species. J. Mamm. 88: 1216-1229.

Hutson, A.M., S.P. Mickleburgh and P.A. Racey. 2001. Microchiropteran bats: global status survey and conservation action plan. IUCN/SSC Chiroptera Specialist Group. IUCN, Gland, Switzerland and Cambridge, UK. pp. i-x; 259.

Jameson, H.L. 1909. On a collection of mammals from South Africa. Ann. Mag. Nat. His. ser. 8: 455-474.

Kock, D., G. Csorba and K.M. Howell. 2000. Rhinolophus maendeleo n.sp. from Tanzania, a horseshoe bat noteworthy for its systematics and biogeography (Mammalia, Chiroptera, Rhinolophidae). Senck Biol. 80: 233-239.

Kunz, T.H. and L.F. Lumsden. 2003. Ecology of cavity and foliage roosting bats. In: (T.H. Kunz and M.B. Fenton, eds.) Bat Ecology. The University of Chicago Press, Chicago and London. pp. 3-89.

Kunz, T.H., R. Hodgkinson and C.D. Weise. 2009. Methods of capturing and handling bats. In: (T.H. Kunz and S. Parsons, eds.) Ecological and behavioural methods for the study of bats. The John Hopkins Universit Press, Baltimore. pp. 3-35.

Kunz, T.H., E. Braun de Torrez, D. Bauer, T. Lobova and T.H. Fleming. 2011. Ecosystem services provided by bats. Ann. N.Y. Acad.Sci. 1223: 1-38.

Mason, M.K., D. Hockman, D.S. Jacobs and N. Illing. 2010. Evaluation of maternal features as indicators of asynchronous 
embryonic development in Miniopterus natalensis. Acta Chiropt. 12: 161-171.

Meester, J.A.J., I.L. Rautenbach, N.J. Dippenaar and C.M. Baker. 1986. Classification of Southern African Mammals. Transvaal Museum Monograph, Pretoria. 5: i-xi, 1-359.

Mickleburgh, S.P., A.M. Hutson and P.A. Racey. 2002. A review of the global conservation status of bats. Oryx. 36: 18-34.

Monadjem, A., P.J. Taylor, F.P.D. Cotterill and M.C. Schoeman. 2010. Bats of southern and central Africa: A biogeographic and taxonomic synthesis. Wits University Press, Johannesburg. pp. i-xiii, 1-596.

Norton, P.M. and M. van der Merwe. 1978. Winter activity of bats in a Transvaal highveld cave. SA J. Sci. 74: 216-220.

Racey, P.A. 2009. Reproductive assessment of bats. In: (T.H. Kunz and S. Parsons, eds.) Ecological and behavioral methods for the study bats, second edition. The John Hopkins University Press, Baltimore. pp. 249-264.

Racey, P.A. and A.C. Entwistle. 2003. Conservation ecology of bats. In: (T.H. Kunz and M.B. Fenton, eds.) Bat ecology. The University Chicago Press, Chicago and London. pp. 680-744.

Rautenbach, I.L. 1982. Mammals of the Transvaal. Ecoplan Monograph, Pretoria. 1: 1-211.

Readers Digest. 1984. Atlas of Southern Africa. Reader's Digest Association South Africa, Cape Town. pp. 256.

Schmidt, D.F., C.A. Ludwig and M.D. Carleton. 2008. The Smithsonian Institution African Mammal Project (1961-1972): an annotated gazetteer of collecting localities and summary of its taxonomic and geographic scope. Smith. Con. Zoo. 628: viii; 320.

Sheffield, S.R., J.H. Shaw, G.A. Heidt and L.R. McClenaghan. 1992. Guidelines for the protection of bat roosts. J. Mamm. 73: 707-710.

Sikes, R.S., W.L. Gannon and the Animal Care and Use Committee of the American Society of Mammalogists. 2011. Guidelines of the American Society of Mammalogists for the use of wild mammals in research. J. Mamm. 92: 235-253.

Simmons, N.B. and R.S. Voss. 2009. Collection, preperation, and fixation of bat specimens and tissues. In: (T.H. Kunz and S. Parsons, eds.) Ecological and behavioral methods for the study bats, second edition. The John Hopkins University Press, Baltimore, MD. pp. 849-867.

Struebig, M.J., T. Kingston, A. Zubaid, S.C. Le Comber, A. Mohd-Adnan, A. Turner, J. Kelly, M. Bożek and S.J. Rossiter. 2009. Conservation importance of limestone karst outcrops for Palaeotropical bats in a fragmented landscape. Bio. Cons. 142: 2089-2096.

Taylor, P.J., S. Stoffberg, A. Monadjem, M.C. Schoeman, J. Bayliss and F.P.D. Cotterill. 2012. Four new bat species (Rhinolophus hildebrandtii complex) reflect Plio-Pleistocene divergence of dwarfs and giants across an Afromontane archipelago. PLoS One 7(9): e41744.

Thomson, B. 2002. Australian Handbook for the Conservation of Bats in Mines and Artificial Cave-Bat Habitats. Australian Centre for Mining Environmental Research, Kenmore, Queensland. pp. 65.

van der Merwe, M. 1973. Aspects of social behaviour in the Natal clinging bat Miniopterus schreibersi natalensis (A. Smith, 1834). Mammalia 37: 379-389.

van der Merwe, M. 1975. Preliminary study on the annual movements of the Natal Clinging bat. SA J. Sci. 71: 237-241.

van der Merwe, M. 1979. Foetal growth curves and seasonal breeding in the Natal clinging, Miniopterus schreibersii natalensis. SA J. Zool. 14: 17-21.

van der Merwe, M. 1980. Delayed implantation in the Natal clinging bat Miniopterus schreibersi natalensis (A. Smith, 1834). Proceedings of the 5th International Bat Research Conference, Lubbock, Texas. pp. 123.

van der Merwe, M. 1987. Other bat species in maternity caves occupied by Miniopterus schreibersii natalensis. S.A. J. Wild. Res.17: 25-27.

van der Merwe, M. 1989. Longevity in Schreibers' long-fingered bat. S.A. J. Wild. Res. 19: 87-89.

van der Merwe, M. and R.J. van Aarde. 1989. Plasma progesterone concentrations in the female Natal Clinging Bat (Miniopterus schreibersii natalensis). J. Reprod.Fert. 87: 665-669.

Vincent, S., M. Nemoz and S. Aulagnier. 2011. Activity and foraging habitats of Miniopterus schreibersii (Chiroptera, Miniopteridae) in southern France: implications for its conservation. Hystrix 22: 57-72. 